\title{
Human sociality as spheres of belonging
}

John Mason ${ }^{\mathrm{c}, \mathrm{d}}$

Félix Schoeller ${ }^{\mathrm{a}, \mathrm{b}, \text { * }}$

${ }^{a}$ Centre de recherches interdisciplinaires, Université Paris Descartes, Paris, France

${ }^{\mathrm{b}}$ Institut de Psychologie, Université Paris-Descartes, Paris, France

${ }^{c}$ University of Southern Denmark, Denmark

${ }^{\mathrm{d}}$ The Independent Academy for Free School Teaching, Denmark

*correspondance: felix.schoeller@gmail.com

Abstract: We examine the mechanisms of cooperation and community structuring human decisions and behaviour, with the goal of outlining new models taking into account the importance of social emotions underlying human behaviour. We introduce formal definitions for the terms discussed, emphasizing the role of social emotions in human evolution. Following on from the idea that kinship is a central organising factor in human behaviour, we introduce the concept of 'spheres of belonging' to designate the structure of kinship, in an attempt to explore its attributes and suggest some of its applications.

Keywords: sociality, culture, behaviour, belonging, network science, social signalling.

\section{Introduction}

It is now widely accepted that humans are not solitary hunters but rather social animals whose behaviour is structured in order to allow life in communities of various sizes (Dunbar, 1999; Brewer, 2006; Castiello et al., 2010). More specifically, anthropologists agree that kinship and affiliation are central organizing features of human societies (Kurland \& Gaulin, 2005). Survival depends on our ability to live and work together, to share goals with one another, and to build and communicate knowledge about how to achieve these goals. We might therefore wonder at an increasing tendency towards individualism and insularity observable today at a global scale in modern societies. This article investigates the mechanism of cooperation and community structuring human decisions and behaviour, with the goal of outlining new models for thinking about the nature of the human dynamics involved. We introduce formal definitions for the terms discussed, emphasizing the role of social emotions in human evolution. Following on from the idea that kinship is a central organising factor in human behaviour, we introduce the concept of 'spheres of belonging' to designate the structure of kinship, in an attempt to explore its attributes and suggest some of its applications. 


\section{The need to belong}

In recent years, there has been a growing interest in sociality both as a need governing human behaviour and as an organising feature in human societies. One key emotion studied by scientists regulating human sociality is the individual's sense of (non-) belonging deriving from the need to belong. There are powerful historical and cultural factors underlying the increased focus on this particular aspect of human experience over the past 150 years, but these lie outside the scope of this article. As a concept derived from attachment theory (e.g. Bowlby 1969), belonging features in Maslow's hierarchy of needs (Maslow, 1968, 1971), in Glasser's Choice Theory (Glasser, 1986) and in Putnam's model of social capital (Putnam, 2000). Baumeister and Leary in their seminal work on belonging consider belonging as "a pervasive drive to form and maintain at least a minimum quantity of lasting, positive and significant interpersonal relationships" (Baumeister \& Leary, 1995). This view of belonging as a need (i.e., a driving force) has fostered a wide range of empirical research into the significance of belonging for both physical and mental health (Allen \& Badcock, 2003; Badcock et al., 2017; Cohen \& Wills, 1995; Daley \& Buchanan, 1999; Hagerty, Williams \& Oe, 2002; Hale, Hannum \& Espelage, 2005; Poulton, Caspi \& Milne, 2002; Wadsworth et. al, 2001; Williams, 2007).

At a larger scale and in parallel to this line of research, there has been a growing interest in belonging as an essential element in human social functioning. Social network theory, for example, has analysed the mechanics of information flow and group cohesion in ways similar to those employed for structures of belonging (e.g. Burt, 2000; Granovetter, 1973). Social identity theory is also relevant to the description of group dynamics, as the identity of the individual and of the group are often in some form of symbiosis that can be mirrored in their dynamics. In addition to these lines of research, belonging also has implications for research in political science and governance policy. There has been a political interest in democratic systems, often seen as under threat, as manifest in the work of thinkers such as Putnam (2002), and Guibernau (2013).

In this article, we introduce the concept of 'spheres of belonging' (SoB) as a model for thinking about interpersonal dynamics in social groups. Pace Baumeister and Leary and others, we suggest that these spheres are not the outcome of a social need but rather are inherent to the human biological makeup and as such can be systematised at that level. The need for attachment, although fuelled by survival needs, is seen here as 
deriving from a biological need to belong. While much research has been conducted into attachment and belonging, we hope to show that there is a level beyond attachment, which is best explained within the framework of biology, the history and logic of life. By the same count, while much has already been written about the social consequences of (non-) belonging, spheres of belonging may be able to advance and broaden further our understanding of such social mechanisms in humans.

This article starts by briefly discussing human communication processes that allow life in communities to emerge and the relation between interpersonal signals, resources and emotion. We suggest that there may exist a radical difference between ventral and dorsal regions of the body, reflecting a biologically determined polarity in human perceptions of 'others', dividing human relations with other members of the species into binary opposites of 'us' and 'them'. From this elementary observation, we conjecture that humans function socially through the logic of what we call 'spheres of belonging' (SoB), group units moulded by inclusion in a set that necessarily entails an exclusion zone of those outside the cluster. The most elementary shape of such a sphere is the family unit. We regard these groupings as abstract spheres because they appear to have a threedimensional quasi-organic structure, with a core and a variety of internal relations to their centre. They also allow for interconnecting spheres of belonging in a variety of dimensions. The final sections of the article deal with the structure of SoB, suggesting that there may be something resembling a magnetic charge acting within the sphere and that the level of charge may be subject to, for example, the degree of volition involved in membership, the threat to the subject's genetic survival or that of the group, the level of abstraction, the perceived threat from outside and so on (Brewer, 1999; Brewer, 2007; Kurzban \& Neuberg, 2015). We look briefly at the role of ritual in affirming membership, and compare our notions of SoB with current work in network theory. Finally, we introduce some future research challenges to further explore the nature and significance of spheres of belonging across human cultures and societies.

\section{Human social signalling}

Human beings survive by sharing goals. We cannot access or share these goals directly and so evolution has favoured the development of signals that have permitted and accelerated communication regarding increasingly complex goals. During the first millenia 
of human evolution, the majority of these goals were centred around resources such as food, water, territory, and basic needs such as reproduction, information, sleep, and security. Most of these signals would therefore have to contain information about the location, maintainance, protection of these necessities and their possible extensions through technology. Each of these signals is associated with an emotion that ultimately aims to maintain stable the provision of particular ressources through homeostatic control (Frijda, 1988). These emotions can be described as positive or negative depending on the status of the resource or the degree to which the need is satisfied. For example, hunger is associated with low glucose level in blood, orgasm with the satiation of the reproductive drive, fatigue with stress, shivers with temperature changes, aggression with territorial threat and so on. There exists a large body of literature on emotions, their psychophysiology and the causal direction of the signals. For the purpose of the present article, we simply mean to make it clear that every emotion is related to a set of bodily signals, its physiological signature. Whether this signal causes the emotion, or whether it is caused by it, is a matter of empirical research.

Such signalling mechanisms serve at least two purposes in allowing both internal and external communication of information. First, they permit needs to be registered consciously for the individual, so that someone becomes aware that his biological body requires food when feeling hunger; and if he did not feel the hunger, he might not realise that he had to eat. In other words, hunger keeps the animal alive by regulating a vital parameter. Secondly, these mechanisms allow us to share individual needs with other member of the species. In their primitive forms, such signals are expressed as facial movements, behavioural gestures, or prelinguistic vocalisations such as grunts, howls and so on. In more advanced cultures, these develop into cultural artefacts such as dance, language, song, poetry and the like.

All signalling mechanisms involving sharing are located in the ventral portion of the body and there are no signalling mechanisms in the dorsal regions. This simple fact has important consequences. We meet face to face, shake hands, hug, rub noses, kiss cheeks or even lips, we bow, curtsy, give high fives - a myriad behaviours intended to mark the open and frontal connection between us and our sphere of belonging. We entrust our soft, vulnerable, ventral body parts to the other. And it is a mark of trust, for trust, as we shall see, is essential to the survival of the sphere. By contrast, we face down our enemies, 
shake our fists, stick out our tongues in signals of vomitting, our hackles rise, we cross our arms over our vulnerable chests or turn our backs to them. We keep our distance. Our eye and eyebrow movements and our vocalisations reflect the same patterns. As a consequence and within our sphere of belonging we are open ventrally to ingroup members and, in so being, are necessarily closed dorsally to outgroup others. Unsurprisingly, the structure of language reflects this opposition. We can, then, only share with those who are in front of us. Those who are behind us are, equally necessarily, out of sight. They are, so to speak, beyond the pale, acting in the dark and, possibly, behind our backs. Wide-eyed, we welcome with open arms, we make a clean break, pay lip service, can stomach (or not) a fight, we are in the dark, our hackles rising, we give the cold shoulder, while the other is undercover or underground, in the shadows, and so on.

\section{Evolution of spheres of belonging}

Spheres of belonging exist at multiple levels during the various ages of life and stages of evolution (Dunbar, 1998; Gonçalves, Perra \& Vispignani, 2011). The primary sphere is the nuclear family, the couple which only becomes a genetically viable entity when a child is added. The process, of course, is the ultimate ventral encounter of genitalia interpenetrating, the laying of male seed in the 'ventre' or womb, and the emergence from the womb of the helpless infant, whose first act is a howl of separation and whose second is to attach itself to the mother's breast. This ultimate sphere of belonging embraces mother and child and, containing as it does the past, present and future of this particular set of genes, has primary purpose and power. The bonding mechanisms here depend on genetically endowed fixed hardwired mechanisms (see for example the work of Jouhanneau on pheronomes regulating suckling in human infants). It is significant that recent research indicates that even in the womb twin siblings demonstrate social sensitivity (Castiello et al., 2010).

During its first years, the infant's sole belonging is to a family or its substitute. Other groupings are fluid and only gradually merge into influential spheres of belonging, when, for example, playground games and language begin to play a role in complex learning. Gradually, the child understands that there are spheres outside the family to which parents also belong - often separately. In puberty, when the child becomes fertile, more complex behaviours emerge, identity as exclusively circumscribed by the family's sphere is called 
into question, issues of group identities begin to appear. Belonging to the family's sphere is involuntary and (except in rare cases) unquestioned. The need to make the choice to belong to alternative SoBs makes itself felt. In other words, around the family's central SoB a whole host of subsidiary SoBs have appeared: families of friends, parents' clubs, school classes and so on. Each of these spheres has its periphery to which the child relates.

Some extraneous SoBs will be included within a wider sphere as being accepted while others may not. Behaviours marking inclusion and exclusion suddenly become paramount and are endowed with seemingly vital importance. Children at school during these years may cause serious psychological damage to others, as they ritualise and practise these mechanisms. In many cases they have not yet understood that trust and inclusion allow for easier bridging, and create broader groupings that will be better equipped to handle their own survival. Exclusive groups built around distrust will typically develop behaviours that ensure the group's internal bonding, strengthening their defences, as it were, but limit the range and flexibility of their resources. It is not possible in this short article to detail the many possible forms and structures that SoBs can adopt. It is, however, worth pointing out that the family SoB has a unique cohesive power in that its members will be prepared to sacrifice their lives for the larger unit or for other members (Ellis et al., 2012). SoBs that manage to create a family-like structure can also display this quality ${ }^{1}$. We could say that there is an internal magnetic-like pull holding members of the group together whereby members see the group as being of greater value than themselves. The strength of this field is in direct proportion to the perceived vulnerability of the group. Other SoB, those that have no direct influence on our survival or that of our genes, clearly would muster only faint magnetic charge. We might establish a sphere around our cycling club but we would not lay down our lives for it or its members - not unless we found ourselves in a life-threatening situation together, in which case core elements of the sphere would alter. Such internal structures and polarities of spheres of belonging require targetted experimental data, including both qualitative, subjective firstperson data and quantitative, objective third-person data. Only by bridging the gap

\footnotetext{
${ }^{1}$ Here we refer specifically to Hamilton, W.D. Genetic evolution of social behavior I \& II, Theoretical Biology 7(I): 152, 1964. Leah A. Fredman, L.A., Buhrmester, M.D., Gomez, Fraser, W.T., Talaifar, S., Brannon, S.M., Swann Jr., W.B. Identity Fusion, Extreme Pro-group behaviour, and Path to Defusion, Social and Personality Psychology Compass, 9/9 (2015), pp. 468-480. This is in part what lies behind mass-destructive events such as Jonestown or Heaven's Gate and it may be linked to 'suicide epidemics' among schoolchildren, for example in Ohio in January 2018.
} 
between what it feels like to belong to a human group and what it entails can we hope to understand social phenomena at large.

\section{Internal structure of the sphere of belonging}

Aside from the internal cohesive polarities of the sphere of belonging, it is worth looking at the composition of its inner core and outer 'skin'. At the core of any sphere is an idea, an image, a story, a conception, a model of the world. This is as true of the family as of the cycling club or of the nation. Spheres are made up of individuals creating a social cluster, but they are grouped around a centre that exists only in their mind and brain. At the periphery of the SoB we find what we term its 'skin'. We use the term to indicate the quasi-organic boundary markers that circumscribe the sphere and the sensitivity and volatility that can be found there. There are spheres that require no boundary markers since their members have an ontological, tacit or recognisable bond. This is true of the family, where new members are introduced through elaborate rituals such as baptism or weddings, but also of some secret societies depending on traditionally complex symbolic ceremonies. Some SoBs require physical documentation such as a membership card or a fee, while other require semiotic proof such as clothing or a badge.

Some SoBs are closed. The family is one such, though clearly new members necessarily have to be admitted for its survival. Others are more open and allow admission on certain criteria that match the core values of the sphere. The nation is an interesting sphere of belonging not least in terms of its openness and the difficulty that can arise when agreeing upon its core values. In each of these cases, there are elements that can be regarded as being 'at the periphery', individuals can be regarded as being 'almost belonging'. There may be a child whom the family 'adopted' either officially or not and who is seen as a member. There may be a former member of the cycling club who only manages to come to morning coffees. There may be refugees taken in by a nation, or drop-outs who live in separate and alternative spheres of belonging within the nation, or criminals excluded from participation in its decision-making. For established members, these form a notional 'skin', allowing them to sense whether the conceptual territory of the SoB has been invaded.

The need to belong can be quantified through its regulation, that is, whether it is frustrated or satisfied. Within psychology, needs are essentially the logical equivalence of 
the notion of the forces in physics. A need cannot be observed nor measured, only its effects upon reality and behavior can. The need to belong cannot be physically measured but the emotions regulating sociality can be measured, both physiologically and psychologically. In order to do this, we need to examine the internal and external markers that signal individual or collective belonging to consciousness. In other words, markers that confirm the subjects in her sense of belonging and markers that confirm her status in the social world. Such markers involve the sharing of resources that are meaningful to the individual, such as forms of clothing, food, drink, warmth, safety, or language.

Markers may also include physically personal markers such as tattoos, beards, piercings, bindis, neckrings, woading, hairdos, and much more. Such markers are overt and tantamount to display. There are other markers that are more discrete, sometimes tacit and invisible. These include, for example, the 'old school' tie, the secret handshake, the choice of some accessory, handbag or watch, for example. And there are a host of involuntary markers such as regional accent, table manners, social 'tics' and verbal habits that indicate which subset of a particular sphere the individual belongs to. In some cases, such subsets become - or are perceived as - separate spheres. There is not the space in this article to go into the many relations that underpin such markers, or the relations between markers and spheres, but these are areas for future exploration.

If symbols can be said to represent, consolidate and, if necessary, reinvent the core notion at the heart of a sphere of belonging, rituals are a means to monitor affiliation, allegiance and compliance to it. In a similar fashion to the internal and external signalling mentioned above, a ritual involves collective action that, at each repetition - and it is by nature repetitive - confirms the adherence of each agent to his or her SoB. Whether it is genuflection before the Christian altar, standing for the national anthem or putting up a Christmas tree, the action affirms not only for the agent but also for the SoB that there is continued allegiance to the notion that underlies the SoB' existence (Kertzer, 1988). A simple thought experiment imagining non-compliance with such a ritual can confirm its power. These are, however, rituals of inclusion. There are also rituals of exclusion, which involve the stigmatisation, punishment and even execution of those deemed to have betrayed the SoB or to be outsiders that threaten its existence. Penal systems are effectively a form of enforcement ritual. In many cases, such rituals are associated with purification, and they have a powerful bonding effect on the SoB (Goffman, 1959). 


\section{Spheres of belonging and social network theory}

Spheres of belonging can be compared to structures developed in social network theory. Bott, for example, has shown that the structure of the social group or SoB in which a conjugal dyad is embedded directly affects the behaviours and relations of this dyad (Bott, E. 1957). A study of four network structures (shown in fig. 1) was designed to see which structures were fastest at problem-solving. It showed that star-shaped structures were fastest since peripheral positions chanelled information to the central node, which then took the decision (Bavelas, A., 1950; Leavitt, H., 1951). The star shape enabled the fastest communication. However, as problems increased in complexity, the situation was reversed and the circle shape was found to be fastest (Shaw, M.E., 1964).

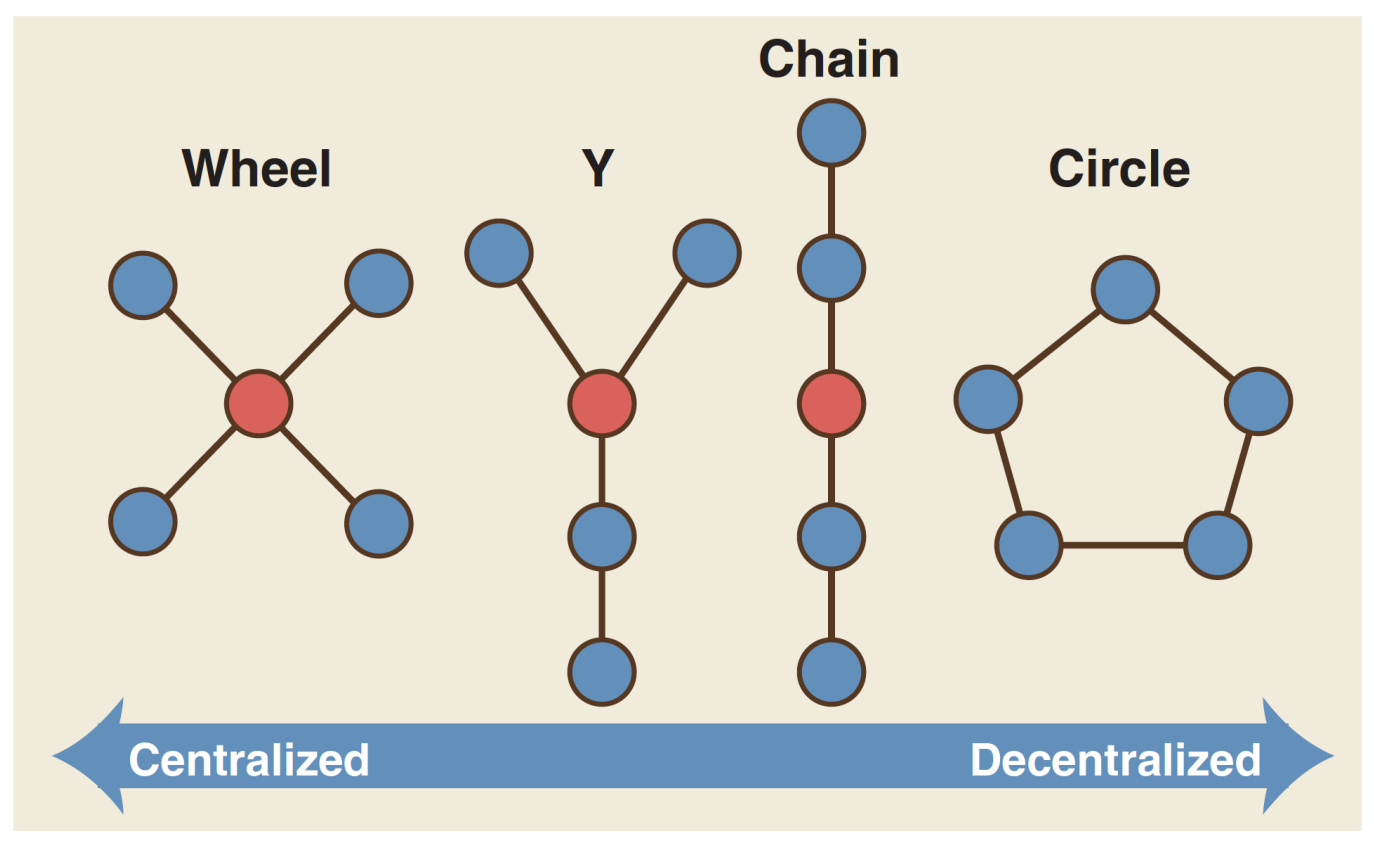

Figure 1.

Four network structures examined by Bavelas and colleagues. Each node represents a person; each line represents a potential channel for interpersonal communication. The most central node in each network is colored red. (from Borgatti et al, 2009)

Similarly, Moreno's 'social atom' theory and Granovetter's work on the relative dynamics relating the strength of weak ties within the social group and the subsequent development of theories of social capital tie in well with SoB structures, as does Borgatti's typology of network ties (fig. 2 below). 


\begin{tabular}{|c|c|c|c|c|c|c|c|c|}
\hline \multicolumn{3}{|c|}{ Similarities } & \multicolumn{3}{|c|}{ Social Relations } & \multicolumn{2}{|c|}{ Interactions } & Flows \\
\hline Location & Membership & Attribute & Kinship & Other & Affective & Cognitive & Affective & \\
\hline $\begin{array}{l}\text { e.g. } \\
\text { same spatial } \\
\text { \& temporal } \\
\text { space }\end{array}$ & $\begin{array}{l}\text { e.g. } \\
\text { same clubs, } \\
\text { same events, etc. }\end{array}$ & $\begin{array}{l}\text { e.g. } \\
\text { same } \\
\text { gender, } \\
\text { same } \\
\text { attitude etc. }\end{array}$ & $\begin{array}{l}\text { e.g. } \\
\text { mother of, } \\
\text { sibling of } \\
\text { etc. }\end{array}$ & $\begin{array}{l}\text { e.g. } \\
\text { friend of, } \\
\text { boss of, } \\
\text { student of, } \\
\text { etc. }\end{array}$ & $\begin{array}{l}\text { e.g. } \\
\text { likes, hates, } \\
\text { etc }\end{array}$ & $\begin{array}{l}\text { e.g. } \\
\text { knows, } \\
\text { knows about, } \\
\text { sees as } \\
\text { happy, } \\
\text { etc. }\end{array}$ & $\begin{array}{l}\text { e.g. } \\
\text { sex with, } \\
\text { talked to, } \\
\text { advice to, } \\
\text { helped, } \\
\text { harmed, } \\
\text { etc. }\end{array}$ & $\begin{array}{l}\text { e.g. } \\
\text { information, } \\
\text { beliefs, } \\
\text { personnel, } \\
\text { resources, } \\
\text { etc. }\end{array}$ \\
\hline
\end{tabular}

Figure 2. A typology of ties studied in social network analysis (from Borgatti et. al, 2009)

The difference between social network theory and the model proposed here is that, rather than deducing patterns from human behaviour, we see the structures and dynamics of SoB as being hardwired into human biology around the primary social need to pool resources, whether those resources be male and female genes or more complex skills clusters needed to perform tasks essential to the group. While the dynamics of kinship may generate the strongest attraction and construct the most impassible boundary to access from without, similar dynamics can be provoked in all spheres under given circumstances. The inward attraction is complemented by an outward repulsion that ensures that undesirable or hostile elements are not admitted. It is not too far-fetched to see the very design of human dwelling and niche construction as a representation of this dynamic, the hearth drawing a circle around it, creating a centre for heat, food and safety not to mention the stories that nourish the core of the group. The group huddled around the fire have their backs to the darkness and around them are the walls of the cave, the hut, the house that mark the boundary of their sphere.

\section{Conclusion}

Conceiving spheres of belonging as comprising a dual polarity may offer new insights into the dynamics of human behaviour. However, it is necessary to assemble much clearer data to underpin further theoretical work. Research is needed to study the evolution of SoBs over time, to explore how shared and individual identities are affected by membership within a sphere, to examine how mechanisms of inclusion and exclusion can be interpreted and predicted using this model, and to establish methods to assess 
individual's belonging within a particular sphere at any given time. To test some of the hypotheses presented in this article, one first needs to develop means of measuring the satiation or frustration of the need to belong - and its effects on mind, brain and behaviour. This would require singling out relevant groups and testing responses to situations such as the introduction of splinter groups, the threat from rival groups and the incidence of 'betrayal' within the group. ${ }^{2}$ Secondly, careful and detailed models of fundamental structures of the SoB need to be delevoped to establish whether the model is indeed workable. A third line of research pertains to the relation between SoB and language, including body language and symbolic language. This needs to be explored further in order to ascertain whether the structures of language and linguistic behaviour bear out any hypotheses. Finally, once the credibility of the model has been established, there would be a need to explore its ramifications, particularly ways in which to influence the degree of 'openness' of a particular SoB - that is a measure of compabilities amongst spheres.

\section{Conflict of Interest}

The authors declare none.

\section{References}

Allen, K-A \& Kern, M.L., School Belonging in Adolescents: Theory, Research and Practice, Springer, 2017

Baumeister, R.F. \& Leary, M.R, (1995) The Need to Belong: Desire for Interpersonal Attachments as a Fundamental Human Motivation, Psychological Bulletin, 117(3), 497-529 Bavelas, A. (1950). Communication Patterns in Task-Oriented Groups. Journal of the Acoustical Society of America, 22, 725-730.

Bott, E. (1957) Family and Social Network, Tavistock Publications, London.

Borgatti, S. P., Mehra A., Brass, D. J. \& Labianca, G., (2009)

Network Analysis in the Social Sciences, Science, 323, 892-895.

Bowlby, J. Attachment and Loss: Volume 1. (1969) New York, NY. Basic Books.

Burt, R. S. (2000). The network structure of social capital. Research in Organizatio nal Behavior, 22, 345-423.

\footnotetext{
${ }^{2}$ Experiments such as the so-called 'Purple Armband' experiment have been conducted.
} 
Brewer, M. B. (1999). The psychology of prejudice: Ingroup love and outgroup hate? Journal of social issues, 55(3), 429-444.

Brewer, M. B. (2007). The importance of being we: Human nature and intergroup relations. American psychologist, 62(8), 728-738.

Castiello, U., Becchio, C., Zoia, S., Nelini, C., Sartori, L., Blason, L., et al. (2010) Wired to Be Social: The Ontogeny of Human Interaction. PLoS ONE 5(10): e13199. https://doi.org/10.1371/journal.pone.0013199 Daley, A.J., \& Buchanan, J. (1999) Aerobic dance and physical self-perceptions in female adolescents: Some implications for physical education. Research Quarterly for Exercise and Sport, 70, 196-200.

Dunbar, R. I. (1998). The social brain hypothesis. Evolutionary Anthropology: Issues, News, and Reviews: Issues, News, and Reviews, 6(5), 178-190.

Ellis, B. J., Del Giudice, M., Dishion, T. J., Figueredo, A. J., Gray, P., Griskevicius, V., ... \& Wilson, D. S. (2012). The evolutionary basis of risky adolescent behavior: implications for science, policy, and practice. Developmental psychology, 48(3), 598-623.

Frijda, N. H. (1988). The laws of emotion. American Psychologist, 43(5), 349-358.

Gonçalves, B., Perra, N., \& Vespignani, A. (2011). Modeling users' activity on twitter networks: Validation of dunbar's number. PloS one, 6(8), e22656.

Glasser, W. (1986) Control theory in the classroom, NY, Perennial Library/Harper \& Row. Goffman, E. (1959) Stigma: Notes on the Management of Spoiled Identity. Prentice-Hall. Granovetter, M. S. (1973). The strength of weak ties. American Journal of Sociolog y, 78(6), 1360-1380.

Guibernau, M. (2013) Belonging: Solidarity and Division in Modern Societies, Polity Press. Hagerty, B.M., Williams, R.A., \& Oe, H., (2002) Childhood antecedents of adult sense of belonging. Journal of Clinical Psychology, 58, 793-801.

Hale, C.J., Hannum, J.W., \& Espelage, D.L., (2005) Social support and physical health: The importance of belonging. Journal of American College Health, 53, 276-284.

Jouhanneau, M., Schaal, B., \& Coureaud, G. (2016) Mammary pheromone-induced odour learning influences sucking behaviour and milk intake in the newborn rabbit, Animal Behaviour, 111, 1-11.

Kertzer, D. I. (1988) Ritual, Politics and Power, London and New Haven: Yale University Press. 
Kurzban, R., \& Neuberg, S. (2015). Managing ingroup and outgroup relationships. The handbook of evolutionary psychology, 653-675.;

Leavitt, H. (1951) Some Effects of Certain Communication Patterns on Group Performance. The Journal of Abnormal and Social Psychology, 46, 38-50.

Kurland, J. A., \& Gaulin, S. J. C. (2005). Cooperation and competition among kin, in Buss, D. (ed.), Handbook of Evolutionary psychology (pp. 447-482). New York: Academic Press Maslow, A.H, (1968) Towards a psychology of being. New York, NY: D. Van Nostrand. Maslow, A.H., (1971) The Farther Reaches of Human Nature, NY, Viking. Poulton, R., Caspi, A., \& Milne, B.J. (2002) Association between children's experience of socioeconomic and adult health: A life-course study. Lancet, 360(9346), 1640-1645.

Putnam, R. (2000) Bowling alone: The collapse and revival of American community, NY, Simon \& Schuster.

Putnam, R.(ed), (2002) Democracies in Flux, Oxford University Press.Shaw, (1964) Communication networks, in L. Berkowitz (ed.), Advances in Experimental Social $p$ sychology, 1, 111, Academic, New York.

Wadsworth, M.E., Thomsen, A.H., Saltzman, H., Connor-Smith, J.K., \& Compas, B.E. (2001) Coping with stress during childhood and adoloescence: Problems, progress, and potential in theory and research, Psycho-logical Bulletin, 12(1), 87-127 